\title{
Legal Insider Trading and Stock Market Liquidity
}

\author{
Hans Degryse $^{1}$ - Frank de Jong ${ }^{2}$. \\ Jérémie Lefebvre ${ }^{3}$
}

\begin{abstract}
This paper assesses the impact of legal trades by corporate insiders on the liquidity of the firm's stock. For this purpose, we analyze two liquidity measures and one information asymmetry measure. The analysis allows us to study as well the effect of a change in insider trading regulation, namely the implementation of the Market Abuse Directive (European Union Directive 2003/6/EC) on the Dutch stock market. The first set of results shows that, in accordance with theories of asymmetric information, the intensity of legal insider trading in a given company is positively related to the bid-ask spread and to the information asymmetry measure. We also find that the Market Abuse Directive did not reduce significantly this effect. Secondly, analyzing liquidity and information asymmetry around the days of legal insider trading, we find that small and large capitalization stocks see their bid-ask spread and the permanent price impact increase when insiders trade. For mid-cap stocks, only the permanent price impact increases. Finally, we could not detect a significant improvement of these results following the change in regulation.
\end{abstract}

Keywords Insider trading - Financial markets regulation - Stock market liquidity · Information asymmetry

The authors thank the discussant and the seminar participants at the Netherlands Authority for the Financial Markets (AFM), and at the Louvain School of Management.

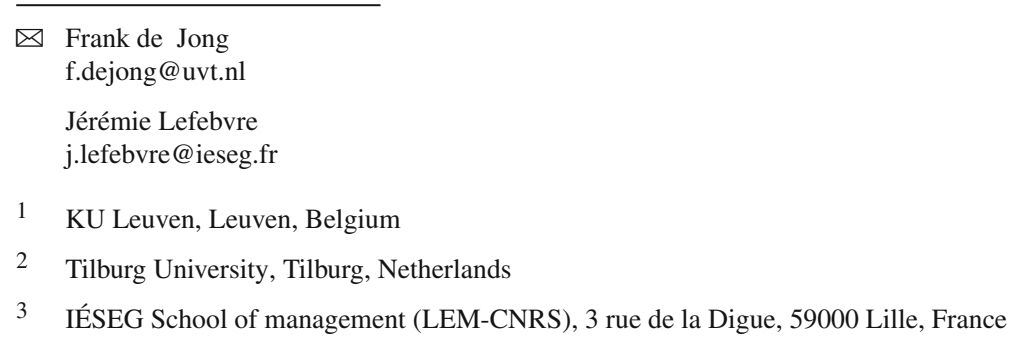




\section{JEL Classification $\mathrm{G} 14 \cdot \mathrm{G} 18$}

\section{Introduction}

In this paper, we study stock market liquidity around dates of legal insider trading in the Netherlands. Trades by corporate insiders are highly regulated, especially since the European Union directive called "Market Abuse Directive" (European Union Directive 2003/6/EC) was incorporated into the Dutch national regulation. Even so, insiders are known to have better information than outside investors about the future prospects of their firm (see e.g. Degryse et al. 2014). In this context, we investigate whether legal trades by insiders in shares of their own company have an impact on the stock's liquidity.

Market liquidity of a firm's stock is a characteristic that determines partially the risk of the firm's equity and thus the cost of capital. It also affects trading costs to outsiders. Both have an important effect of corporate finance decisions (see esp. Amihud and Mendelson 2008). For this reason, it is important to understand how corporate insiders affect their company's stock liquidity when they trade.

The Market Abuse Directive aims at tightening and at expanding stock market regulation regarding market abuse and manipulation, and in particular insider trading. Its goal is also to harmonize the legislation in countries of the European Union. Incorporated into Dutch regulation on October 1st, 2005, the two aspects of this new regulation that are important for our study are, first, the strengthening of monitoring and punishment of illegal insider trading. Therefore, corporate insiders are less likely to trade upon inside information. Second, the new regulation obliges listed companies to disclose through press releases any information that is relevant for the valuation of the stock. As such, if companies disclose more information, then corporate insiders should in principle have less information advantage over outside investors. These two effects together should decrease the information asymmetry of corporate insiders' trades.

Our contribution on this subject is analyzing whether the effect of insider trading on the stock's liquidity changed after the implementation of this European Union wide regulation. We tackle this topic by studying data from the Netherlands. The research questions analyzed in this paper are the following. How do legal insider trades affect stock market liquidity? Do the bid-ask spread and price impact increase? Does the implementation of the European Union Market Abuse Directive reduce the effect of insider trading on the liquidity of the stocks?

Two approaches are used to analyze these research questions. A first approach looks at the effect of the intensity, or the prevalence, of insider trading on the average stock liquidity and permanent price impact. This is a cross-sectional approach. The second approach proceeds by looking more closely at the short-term effect around dates of legal insider trading. More specifically, we calculate the impact on a stock's illiquidity induced by the presence of corporate insiders on the market, by subtracting illiquidity measures on the date of the trading by the same measure obtained during a benchmark period. We label this as "abnormal illiquidity". This is repeated for each insider trading event and for each firm. This abnormal illiquidity is then analyzed in a regression framework. The goal is to assess whether the presence of informed traders creates 
abnormal illiquidity, be it by enlarging the bid-ask spread or the adverse selection component of the spread (as measured by the permanent price impact of trades).

Our findings are that insider trading is important to explain liquidity both on the cross-section and around event dates. On the cross-section, stocks with more insider trading have wider spreads and a larger permanent price impact. Also, we show that the Market Abuse Directive helped to reduce this effect. On a finer time frame, we found that on days of insider trading, the spreads and price impact are larger than on other days (this is true mostly for small and large companies, but it is less the case for medium-sized stocks). This analysis did not allow us to identify a positive effect of the Market Abuse Directive.

This paper brings together three strands of literature, the first of which is about legal insider trading. Several papers show that legal insider trading helps to predict future stock price performance (see e.g. Seyhun 1998; Lakonishok and Lee 2001; Jeng et al. 2003; Fidrmuc et al. 2006; Degryse et al. 2014). This is consistent with trades by corporate insiders being perceived by other stock market participants as based partly on private information. The current paper extends this literature by analyzing whether a stock's liquidity measures on dates of insider trading are different compared to non insider trading days.

The second strand of literature related to our study includes papers that analyze market liquidity around information events. For example, Lee et al. (1993), Krinsky and Lee (1996) and Kavajecz (1999) study the bid-ask spread and adverse selection costs around earnings announcements. Aktas et al. (2007) study the probability of informed trading (PIN) around merger and acquisition announcements. This literature, like the present paper, aims at testing empirical implications of theoretical market microstructure models of adverse selection (see e.g. Kyle 1985; Glosten and Milgrom 1985; O'Hara 1995 or de Jong and Rindi 2009 provide a review of these models).

This paper also relates to the literature about financial market regulation, and specifically about insider trading regulation. It thus contributes to the debate about the efficiency of insider trading regulations (see e.g. Bainbridge 2000; Bhattacharya and Daouk 2002). For this purpose, we also analyze the effect of a change in regulation concerning insider trading on the Dutch stock market. A similar analysis of a change in insider trading regulation is done by Frijns et al. (2008) for the New Zealand Stock Exchange. The authors study whether the average adverse selection component of the spreads of all stocks on the exchange changed when new regulations about insider trading were adopted in New Zealand. They find a reduction of adverse selection after the implementation of the regulation. While their paper only investigates liquidity measures around the change in regulation, the present paper goes one step further by also looking specifically on dates where insiders traded.

The literature studying legal insider trading and effects on market liquidity is scarce. The existing papers use a cross-sectional approach to compare the impact of insider trading on spreads across firms. Chung and Charoenwong (1998) study the bid-ask spread of US stocks and relate it to legal insider trading. They find that in average, firms with larger extent of legal insider trading have larger spreads, but contrary to our results, they do not find evidence that spreads increase in the period around legal insider trading. Khan et al. (2005) study the impact of insider trading on market liquidity in the NASDAQ market. They obtain mixed results and provide the interpretation that 
dealers are unable to detect informed investors on the market. We improve upon these studies by analyzing more sophisticated measures of the spread including the adverse selection component. In addition, we extend the results for a different market structure, which is, in our case, a fully automated limit order book market. Also related to this strand of literature, Aktas et al. (2008) study the contribution to price discovery that is due to legal insider trading. Garfinkel and Nimalendran (2003) and Gleason (2007) study the difference in response to insider trading by market makers between NASDAQ and NYSE.

A recent analysis similar to ours was done in the Hong Kong stock exchange (Cheng et al. 2006) using a different methodology from ours. They perform a pooled cross-section and time series regression of daily liquidity measures (calculated using intraday data) on explanatory variables and on a dummy variable to identify insider trading days. Consistent with our finding, they find that liquidity and depth is negatively affected by insider trades.

The rest of this paper is organized as follows. Section 2 introduces the data and the methodology, and provides descriptive statistics about different liquidity measures. Section 3 presents results of a cross-sectional analysis of the effect of intensity of legal insider trading on the average liquidity of stocks. Section 4 presents a day-byday analysis of the effect of legal insider trading on the stock's liquidity. Finally, Sect. 5 concludes.

\section{Data and Methodology}

Our data on legal insider trading is obtained from the AFM (Authority for the Financial Markets, the Dutch financial markets supervisor). The dataset consists of the days for which a corporate insider traded shares, for each stock. Unfortunately, the trade time during the day is not included in the dataset, rendering it impossible to study intraday changes in a stock's liquidity. We use only trades in shares by Directors and Board members (top executives). Trades related to option exercise are excluded. ${ }^{1}$ When many insiders from the same company trade during a given day, we aggregate the order flow, so that for each company-date pair we can determine whether it is an insider net purchase date or an insider net sale date.

Prior to October 2005, the main article of law that regulated insider trading by directors and board members was the Act of the Disclosure of Major Holdings of 1996 (Wmz 1996). In 1999, an important change to this regulation was introduced: all corporate insiders had to notify their trades in their own company's stock to a public registry. The reporting delay was set to 10 days after the end of the month in which the trade occurred. In 2002, this reporting delay was reduced to one business day for top executives, i.e. the insiders analyzed in this paper. In October 2005, the Market Abuse Directive (European Union Directive 2003/6/EC) was implemented into the Dutch law. This new regulation increased substantially the punishment to illegal insider

\footnotetext{
1 For example, insiders often sell shares immediately after having acquired them through a stock option scheme. Such sales are not taken into account in the present analysis. Degryse et al. (2014) and Cziraki et al. (2013) analyze option exercise by corporate insiders in the Netherlands.
} 
trading and made it mandatory for listed firms to disclose price-sensitive information through press releases. One of the concerns that led to this regulation was that insiders were incited to trade in advance of important company news announcements (AFM 2007). Raising the penalty to this behavior and requiring every company to publish news announcements on a timely manner aimed at reducing information leakage and, therefore, increasing market cleanliness. According to AFM (2007), the new regulation reduced information leakage prior to press releases mainly for small firms, as well as technological firms. These firms have typically lower governance structures and thus are more prone to suspicious insider trading. In contrast, large firms often have very stringent rules about their executives' trades (e.g. executives are allowed to trade only during a certain window after earnings announcements). Therefore, we hypothesize that small firms will have a larger effect of insider trading on their stock's liquidity and price impact. Also, we expect to find a stronger effect of the new regulation for these firms. We refer to Degryse et al. (2014) for more detail about the dataset and the institutional and regulatory details concerning insider trading in the Netherlands.

In order to compute liquidity measures and the price impact, we use high frequency data from Euronext Amsterdam. The database contains all executed trades and best quotes, and covers the period from July 2004 to December 2007. We use also Datastream to obtain the market capitalization of stocks in the sample.

\subsection{Methodology}

Two measures of liquidity and one measure of adverse selection are computed on a daily basis. The first measure is the quoted spread. It is defined as the relative spread between the best ask and the best bid for a given stock on a given date:

$$
Q S=\frac{1}{T} \sum_{t=1}^{T} \frac{A_{t}-B_{t}}{m_{t}}
$$

where the $T$ quotes that appear during the trading day are used, and where $A_{t}$ and $B_{t}$ are the best ask price and the best bid price, respectively, at each quote update. $m_{t}$ is the mid-quote defined as $\left(A_{t}+B_{t}\right) / 2$.

The second measure, the effective spread, is twice the relative spread between the trade price and the prevailing mid-quote:

$$
E S=\frac{2}{T} \sum_{t=1}^{T}\left|\frac{P_{t}-m_{t}}{m_{t}}\right| .
$$

Here, the spread is computed for the $T$ trades that occur during the trading day. The difference between this measure and the previous quoted spread is that a trade can "walk up" the order book in case the trade size is larger than the outstanding best quote. In that case the trade price might be larger than the best ask in case of a purchase order, or lower than then best bid in case of a sell order. The effective spread takes this into account. 


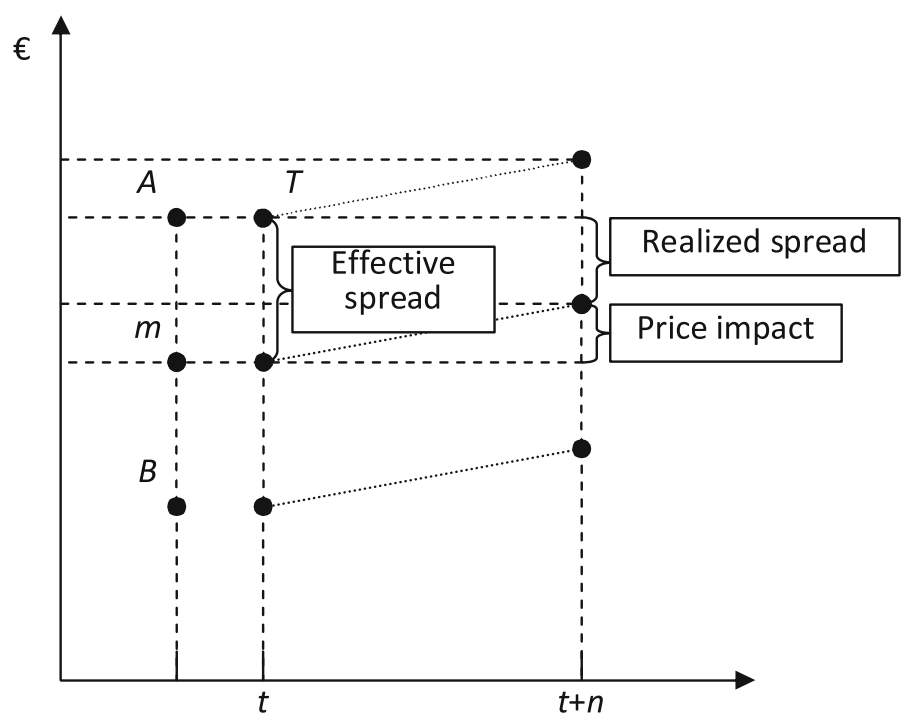

Fig. 1 Illustration of the spread measures. This figure illustrates the liquidity measures. $A$ is the best ask quote, $B$ is the best bid quote, $m$ is the mid-quote and $T$ is the price at which the trade executes. The effective spread is the difference between the transaction price and the quote mid-point. The trade occurs at time $t$. At time $t+n$ the realized spread (the difference between the transaction price and the future quote mid-point) and the price impact (the difference between the quote mid-point at the time of the trade and the future quote mid-point) are measured. Note that in this figure, the trade occurs at the prevailing ask price. It does not have to be so

The measure of adverse selection that we use is the permanent price impact ${ }^{2}$ defined as twice the relative spread between the prevailing quote mid-point at the time of a trade, and the future quote mid-point:

$$
P I=\frac{2}{T} \sum_{t=1}^{T} q_{t} \frac{m_{t+n}-m_{t}}{m_{t}},
$$

where $q_{t}$ is the direction of the trade ( +1 for a purchase and -1 for a sale). We use several time frames to determine the future quote mid-point (i.e. the value of $n$ ), ranging from $1 \mathrm{~min}$ to $1 \mathrm{~h}$ (see Sect. 2.2). To compute all three measures, we discard opening and closing auctions, as well as cross-trades. Figure 1 helps to understand the meaning of these measures by showing an example of a purchase.

In order to perform a cross-sectional analysis, we use two different proxies for the intensity, or prevalence, of legal insider trading. The first intensity measure, $I N T^{1}$, is the total number of shares traded by insiders for a given company, scaled by the number of shares outstanding. The second intensity proxy, $I N T^{2}$, is the number of insider trading days over the total number of trading days; in other words, the proportion of trading days with legal insider trading. We hypothesize that the more days with insider trading,

\footnotetext{
2 The use of the permanent price impact as a measure of informational content of trades is due to Huang and Stoll (1996) and Bessembinder and Kaufman (1997).
} 
the more information asymmetry there is between market participants and insiders, and thus the less liquid the stock will be.

To analyze the behavior of the spread around dates of insider trading, we use a methodology that closely resembles the event study methodology. "Abnormal Illiquidity", or $A I$ for short is a daily measure of change in liquidity compared to a benchmark liquidity. ${ }^{3}$ The idea is to subtract a given measure of illiquidity of a stock on a day by the expected illiquidity, or benchmark illiquidity. The illiquidity measures used are the quoted bid-ask spread, the effective bid-ask spread, and the permanent

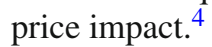

More formally, Abnormal Illiquidity for stock $i$ on event date $t$ is measured as follows:

$$
A I_{i t}=\text { Illiquidity }_{i t}-\text { Benchmark }_{i t},
$$

where the Benchmark illiquidity is computed by averaging the measure of illiquidity on days -10 until +10 around the insider trading day, excluding days 0 to 4 (i.e. five trading days starting on the date of insider trading). The Abnormal Illiquidity can thus be obtained for five days: the date of insider trading itself, and the following four trading days. The rationale for using a window of five days to measure Abnormal Illiquidity is because it might be possible that market participants detect the presence of insiders with a delay, and they might adjust the bid-ask spread with some lag. This is a similar approach to other papers in the literature that perform short-term event studies on market microstructure effects. Researchers typically use shorter estimation and event windows compared to the traditional event study methodology. Chung and Charoenwong (1998) use as event period a window of five days before and after the event date, and as benchmark period 15 days before and after the estimation period. Garfinkel and Nimalendran (2003) also perform a short-term event study with microstructure measures. They compare liquidity measures on insider trading dates, i.e. a one-day event window, with a benchmark of five trading days. Moreover, Chung and Charoenwong (1998) find that there is a change in the bid-ask spread on date of insider trading and also to some extent on some following days. But no change is detected in liquidity and market conditions before the insider trading date. For these reasons, it is reasonable for us to take an event window of five days starting on the insider trading date, and an estimation window of 16 days around the event window.

The Abnormal Illiquidity measures from day 0 to day 4 , for a given stock, are then added up to obtain what we call Cumulative Abnormal Illiquidity $(C A I)$. This measure is to be interpreted simply as the sum of the above average illiquidity of the stock over five days.

The methodology used allows to test whether the CAI's are statistically different from zero and closely follows the event study methodology. ${ }^{5}$ The $C A I$ 's for all the stocks and events of insider trading are then averaged. We thus obtain the average

\footnotetext{
3 The concept of Abnormal Illiquidity measure is analogous to Abnormal Returns, used in event studies.

4 When the bid-ask spread increases, the stock is less liquid. This is why we call it a measure of illiquidity.

5 The following description of the test statistic is analogous to the $J_{2}$ statistic for standard event studies as exposed in Campbell et al. (1997), chapter 4.
} 
$C A I$ due to the presence of insiders on the market. To test whether the average $C A I$ is different from zero, we first standardize each $C A I$ by its estimation error, then we aggregate these standardized $C A I$ 's to obtain a statistic that has a known distribution, from which we obtain the critical values. The standardized $C A I$, or $S C A I$, for event $i$ is:

$$
S C A I_{i}=\frac{C A I_{i}}{\operatorname{st}-\operatorname{err}\left(C A I_{i}\right)}
$$

Each individual standardized $C A I$ is distributed as a Student $t$ distribution with $m-1$ degrees of freedom, where $m$ is the number of observations used to compute the benchmark illiquidity (in our case, $m=16$ ). The variance of this distribution is $\frac{m-1}{m-3}$.

Define $\overline{S C A I}$ as the average standardized $C A I$ :

$$
\overline{S C A I}=\frac{1}{N} \sum_{i=1}^{N} \frac{C A I_{i}}{\operatorname{st}-\operatorname{err}\left(C A I_{i}\right)} .
$$

Then

$$
\operatorname{var}(\overline{S C A I})=\frac{1}{N} \frac{m-1}{m-3},
$$

because we assume no cross-correlation betwen $C A I_{i}$ and $C A I_{j}$, for $i \neq j$. As a result, the following statistic, called simply $z$, is distributed as standard normal:

$$
z=\sqrt{N \frac{m-3}{m-1}} \overline{S C A I} \sim N(0,1)
$$

The $z$ statistic is used to make inferences about the average cumulative abnormal illiquidity.

\subsection{Descriptive Statistics}

Table 1 presents descriptive statistics about insider trades and the companies in the sample. To get an idea of how these statistics change with company size, we separate into market capitalization terciles. Also, for some statistics, we show how they change before and after the implementation of the Market Abuse Directive (MAD).

Panel A of Table 1 shows the incidence of insider trading. We see that companies have from 7.2 to 15.3 insider trades per year, depending on their size, with an overall average of about 10 insider trades per firm per year. These numbers are of comparable magnitude to the sample used by Chung and Charoenwong (1998), which represents the US market during the year 1988 (they have an average of 10 insider trades per firm per year). However, in our sample, insider trades represent a lower proportion of all trades compared to Chung and Charoenwong's sample $(0.006 \%$ in our sample compared to $0.07 \%$ in theirs). Panels $\mathrm{B}$ and $\mathrm{C}$ show the size of trades by insiders as proportion of shares outstanding (Panel B) and in value (Panel C). In every case, the mean is much larger than the median, indicating a large skewness. Insider trade 
Table 1 Descriptive statistics

\begin{tabular}{|c|c|c|c|c|}
\hline & Small & Medium & Large & All \\
\hline \multicolumn{5}{|c|}{ Panel A: Average number of trades per year } \\
\hline Insider trades & 7.2 & 6.3 & 15.3 & 10.1 \\
\hline Non insider trades & 19,468 & 65,269 & 343,477 & 162,923 \\
\hline Percentage of insider trades & $0.037 \%$ & $0.010 \%$ & $0.004 \%$ & $0.006 \%$ \\
\hline \multicolumn{5}{|c|}{ Panel B: Insider trade size scaled by shares outstanding $(\times 1000)$} \\
\hline \multicolumn{5}{|l|}{ All periods } \\
\hline Mean & 10.11 & 2.89 & 0.44 & 3.96 \\
\hline Median & 0.303 & 0.274 & 0.020 & 0.114 \\
\hline \multicolumn{5}{|l|}{ Before MAD } \\
\hline Mean & 7.91 & 5.21 & 0.80 & 4.02 \\
\hline Median & 0.244 & 0.289 & 0.012 & 0.083 \\
\hline \multicolumn{5}{|l|}{ After MAD } \\
\hline Mean & 10.91 & 0.75 & 0.23 & 3.92 \\
\hline Median & 0.335 & 0.248 & 0.025 & 0.125 \\
\hline \multicolumn{5}{|c|}{ Panel C: Insider trade value (thousand euros) } \\
\hline \multicolumn{5}{|l|}{ All periods } \\
\hline Mean & 818.5 & 835.4 & 694.3 & 774.5 \\
\hline Median & 51.9 & 111.6 & 78.8 & 82.8 \\
\hline \multicolumn{5}{|l|}{ Before MAD } \\
\hline Mean & 557.7 & 1036.5 & 276.3 & 641.6 \\
\hline Median & 8.9 & 98.4 & 59.8 & 60.8 \\
\hline \multicolumn{5}{|l|}{ After MAD } \\
\hline Mean & 913.7 & 650.2 & 941.7 & 854.7 \\
\hline Median & 74.7 & 169.8 & 94.8 & 99.1 \\
\hline \multicolumn{5}{|l|}{ Panel D: INT ${ }^{1}$} \\
\hline \multicolumn{5}{|l|}{ All periods } \\
\hline Mean & 57.8 & 11.4 & 14.8 & 27.9 \\
\hline SD & 131.4 & 39.9 & 48.0 & 85.8 \\
\hline \multicolumn{5}{|l|}{ Before MAD } \\
\hline Mean & 34.0 & 11.8 & 16.5 & 21.8 \\
\hline SD & 52.6 & 43.9 & 59.4 & 52.6 \\
\hline \multicolumn{5}{|l|}{ After MAD } \\
\hline Mean & 85.1 & 11.1 & 13.4 & 33.2 \\
\hline SD & 182.7 & 37.7 & 37.8 & 106.6 \\
\hline \multicolumn{5}{|l|}{ Panel E: INT $T^{2}$} \\
\hline \multicolumn{5}{|l|}{ All periods } \\
\hline Mean & $1.53 \%$ & $1.20 \%$ & $1.82 \%$ & $1.52 \%$ \\
\hline SD & $2.32 \%$ & $1.19 \%$ & $2.96 \%$ & $2.27 \%$ \\
\hline
\end{tabular}


Table 1 continued

\begin{tabular}{|c|c|c|c|c|}
\hline & Small & Medium & Large & All \\
\hline \multicolumn{5}{|l|}{ Before MAD } \\
\hline Mean & $1.86 \%$ & $1.08 \%$ & $1.49 \%$ & $1.51 \%$ \\
\hline $\mathrm{SD}$ & $2.95 \%$ & $1.09 \%$ & $1.64 \%$ & $2.12 \%$ \\
\hline \multicolumn{5}{|l|}{ After MAD } \\
\hline Mean & $1.15 \%$ & $1.29 \%$ & $2.08 \%$ & $1.52 \%$ \\
\hline $\mathrm{SD}$ & $1.24 \%$ & $1.27 \%$ & $3.71 \%$ & $2.41 \%$ \\
\hline \multicolumn{5}{|c|}{ Panel F: Average daily number of trades } \\
\hline \multicolumn{5}{|l|}{ Number of stock-days } \\
\hline Non insider trading days & 1981 & 2113 & 2380 & 6474 \\
\hline Insider trading days & 259 & 306 & 386 & 951 \\
\hline \multicolumn{5}{|l|}{ Mean number of trades } \\
\hline Non insider trading days & 75 & 258 & 1698 & 731 \\
\hline Insider trading days & 76 & 273 & 1441 & 694 \\
\hline \multicolumn{5}{|l|}{ Mean trade size (euros) } \\
\hline Non insider trading days & 1008 & 1603 & 2497 & 1750 \\
\hline Insider trading days & 1346 & 1515 & 2425 & 1838 \\
\hline \multicolumn{5}{|c|}{ Panel G: Market capitalization (million euros) } \\
\hline Market capitalization & 139 & 620 & 15,400 & 6358 \\
\hline
\end{tabular}

This table shows descriptive statistics about the companies in the sample, trades by insiders, and normal trades that execute on the Euronext stock market. Panel A shows market capitalization, obtained by multiplying the price per share by the total number of shares outstanding at the beginning of each calendar year. Panel B shows the mean and median size of trades by insiders, for the period before the implementation of Market Abuse Directive (MAD), after its implementation as well as for the whole period. Panel C shows the insider trade sizes in euros. Panels D and E show the mean and standard deviation of the intensity measures: INT $^{1}$ is computed as the total shares traded by insiders scaled by the number of shares outstanding in thousands. $\mathrm{INT}^{2}$ is the percentage of trading days with insider trading. Panels $\mathrm{F}$ and $\mathrm{G}$ show statistics about the trades executed on the Euronext platform: number of stock-days observations, the mean number of trades per day and the mean trade size in euros

sizes as a proportion of shares outstanding are smaller for larger companies. In terms of value traded, there is no clear pattern with respect to firm size. Panels D and E show the mean and standard deviation of the intensity measures $I N T^{1}$ and $I N T^{2}$. Both variables are fairly stable between periods (before and after MAD). Panel F shows the total number of observations (stock-day pairs), and the number and size of intraday trades, during days without insider trading as well as days with insider trading. We see that the mean trade size is increasing with market capitalization. We see also that the mean number of trades per day as well as the mean trade size in euro is not largely different on days of insider trading compared to days without insider trading. Finally, Panel G shows the market capitalization of the stocks in our sample.

We now determine which intraday time frame is suitable in order to compute the permanent price impact (the index $n$ in Eq. 1). In order to do so, it is useful to show a graph of the price impact as a function of intraday time. See Fig. 2. 


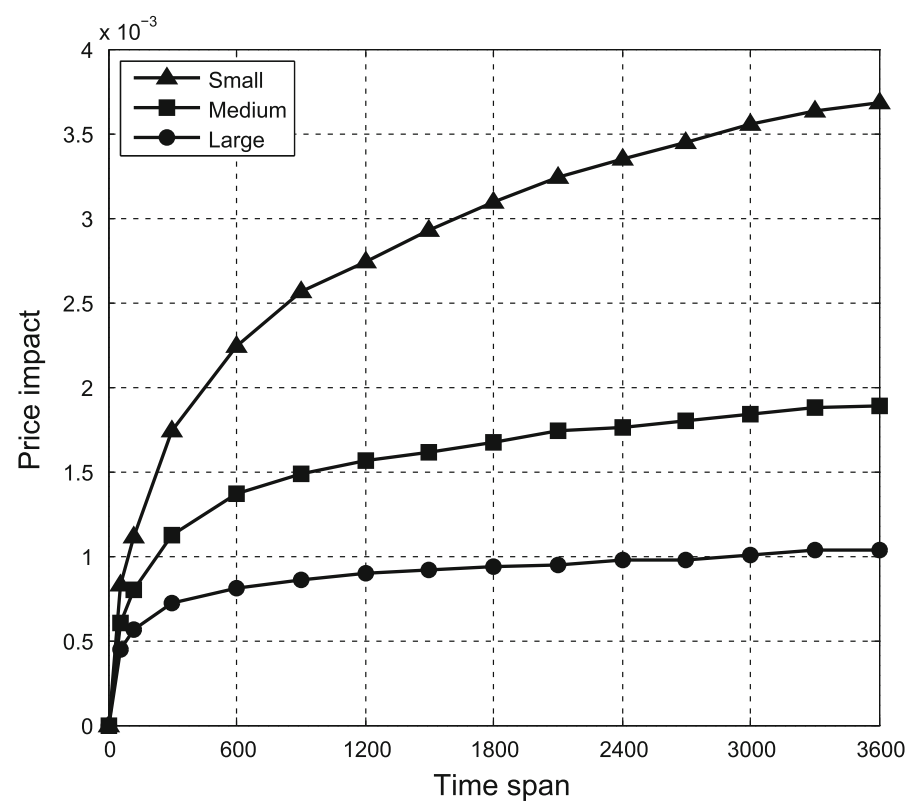

Fig. 2 Price impact. This graph shows the mean price impact of trades, for each market capitalization tercile. The price impact is scaled by the quote mid-point. Time is in seconds. The data used are all days with insider trading plus 10 days prior and after the trades

Using all company-date couples in the sample (insider trading days as well as 10 days prior and after the trading day itself), Fig. 2 shows the realized spread using several time frames: 1, 2, 5, $10 \mathrm{~min}$, and all multiples of $5 \mathrm{~min}$ until $1 \mathrm{~h}$. All trades are used (insider trading dates as well as non insider trading dates). The data are separated into three categories of stocks sorted by market capitalization. The graph shows that it takes some time for the information content of a trade to be incorporated into the quotes. We see also that a different time frame should be used for each size category. For large firms, after $10 \mathrm{~min}$ the price impact curve is practically flat. This means that after $10 \mathrm{~min}$, the information content of the trade is almost entirely impacted in the quotes. For medium firms, a 30-min time frame seems to be reasonable. For small firms, the price impact increases until at least $1 \mathrm{~h}$ after the trade. For this reason, we use 10, 30 and $60 \mathrm{~min}$ time frame for large, medium and small firms, respectively, in order to compute the permanent price impact of each trade.

Table 2 shows some descriptive statistics about the spread measures. Consistent with the literature on market liquidity, the quoted spread and effective spread both are decreasing functions of market capitalization. The (permanent) price impact can be seen as the profits to informed traders. We see that the price impact is larger for small firms. This is consistent with the view that small firms suffer more from adverse selection costs than large firms, since they are typically more opaque, and less followed by the press and by analysts.

In the next section, we analyze how the intensity of insider trading affects the average liquidity and price impact of stocks on the cross-sectional level. 
Table 2 Descriptive statistics of the liquidity measures

This table shows descriptive statistics about the liquidity measures. The quoted spread, the effective spread, and the price impact are in relative terms (i.e. percentage of price). The price impact is computed with an horizon of $10 \mathrm{~min}$ for large firms, $30 \mathrm{~min}$ for medium firms, and $60 \mathrm{~min}$ for small firms. See Sect. 2. The table shows for each market capitalization tercile the mean of the liquidity measures, for days of insider trading as well as days without insider trading. The sample is further separated in the period pre- and post-Market Abuse Directive

\begin{tabular}{llll}
\hline Small & Medium & Large & All \\
\hline
\end{tabular}

Panel A: Quoted spread

Before MAD

$\begin{array}{lllll}\text { Non ins. tr. days } & 1.434 & 0.680 & 0.398 & 0.744 \\ \text { Ins. tr. days } & 1.711 & 0.643 & 0.581 & 0.845 \\ \text { All days } & 1.454 & 0.677 & 0.412 & 0.752 \\ \text { After MAD } & & & & \\ \text { Non ins. tr. days } & 0.844 & 0.372 & 0.140 & 0.460 \\ \text { Ins. tr. days } & 0.891 & 0.369 & 0.518 & 0.602 \\ \text { All days } & 0.848 & 0.371 & 0.179 & 0.473\end{array}$

Panel B: Effective spread

Before MAD

$\begin{array}{lllll}\text { Non ins. tr. days } & 1.334 & 0.605 & 0.370 & 0.681 \\ \text { Ins. tr. days } & 1.569 & 0.562 & 0.545 & 0.768 \\ \text { All days } & 1.351 & 0.602 & 0.384 & 0.688 \\ \text { After MAD } & & & & \\ \text { Non ins. tr. days } & 0.697 & 0.300 & 0.118 & 0.379 \\ \text { Ins. tr. days } & 0.750 & 0.299 & 0.474 & 0.519 \\ \text { All days } & 0.701 & 0.300 & 0.155 & 0.392\end{array}$

Panel C: Price impact

Before MAD

\begin{tabular}{lllll} 
Nns. tr. days & 0.215 & 0.178 & 0.097 & 0.155 \\
Ins. tr. days & 0.343 & 0.215 & 0.149 & 0.217 \\
All days & 0.225 & 0.181 & 0.101 & 0.160 \\
After MAD & & & & \\
Non ins. tr. days & 0.219 & 0.152 & 0.062 & 0.144 \\
Ins. tr. days & 0.296 & 0.188 & 0.103 & 0.190 \\
All days & 0.225 & 0.155 & 0.066 & 0.148 \\
\hline
\end{tabular}

\section{Intensity of Legal Insider Trading}

This section answers the question whether, in the cross-section, liquidity providers on the market adjust the spreads depending on the intensity of insider trading. Since insiders are investors that have informational advantages over other market participants, we hypothesize that liquidity measures will be different depending on the intensity of insider trading, i.e. depending on the likelihood of trading against an insider. As in Chung and Charoenwong (1998), we regress the average stock liquidity on the known explanatory variables, and on the intensity of insider trading. Also, we test for the effect of the change in regulation regime, namely the implementation of the Market Abuse Directive, similarly to Frijns et al. (2008).

The methodology used closely resembles the traditional methodology for analyzing the determinants of the bid-ask spread (see Stoll 2000; Demsetz 1968 for an early 
treatment of this idea). But using a simple cross-sectional regression with one observation per stock, we would not be able to identify the effect due to the Market Abuse Directive. Instead of using one observation per stock, we use one observation per stock-period (pre- and post-MAD). This allows us to use a dummy variable to control for the effect of the new regulation. ${ }^{6}$ Thus, the basis of observation is a stock-period, where each variable is an average over the period. The effect of intensity of insider trading on liquidity and price impact is obtained by adding the intensity measure in the regression. Also, we add a dummy for MAD, to capture the effect of the regulatory regime. Finally, we add an interaction variable between MAD and intensity. The regression equation is the following:

$$
\begin{aligned}
\text { Liq }_{i}= & \beta_{0}+\beta_{1} \log M \operatorname{Cap}_{i}+\beta_{2} \text { Inv Price }_{i}+\beta_{3} \log \operatorname{Vol}_{i}+\beta_{4} \operatorname{Volty}_{i}+\beta_{5} I N T_{i}^{k} \\
& +\beta_{6} M A D_{i}+\beta_{7} M A D \times I N T_{i}^{k}+\varepsilon_{i},
\end{aligned}
$$

where $L i q_{i}$ is the average of the liquidity measure under study (quoted spread, effective spread and price impact, in percentage points); $\log M \mathrm{Cap}_{i}$ is the $\log$ of the market capitalization of stock-period $i$; Inv Price Is $_{i}$ the inverse of the average price, using daily closing prices for stock-period $i ; \log \operatorname{Vol}_{i}$ is the average daily trading volume; Volt $y_{i}$ is the stock's volatility calculated by the standard-deviation of the stock returns over the whole sample period; $I N T_{i}^{k}, k=1,2$, is the intensity of insider trades, either total shares traded, scaled by the number of shares outstanding in thousands $(k=1)$, or proportion of days with insider trading $(k=2)$. We add an interaction variable of the regulatory regime and insider trading intensity, $M A D \times I N T_{i}^{k}$, that will capture any difference in the effect of insider trading intensity on the spread before and after the implementation of the Market Abuse Directive. We use standard errors consistent for heteroskedasticity and clustering, since most companies enter the regression twice and therefore their liquidity measures might not be independent for each observation. The results of the regression are shown in Table 3.

The results show that the intensity of insider trading has an effect on the average stock liquidity, after controlling for other factors. Both specifications (i.e. model (1) with $I N T^{1}$ and model (2) with $I N T^{2}$ ) have positive coefficients for intensity of insider trading on the quoted spread, the effective spread, and permanent price impact. The coefficients are statistically significant for model (1). For model (2), intensity of insider trading has a significant effect only for the effective spread. ${ }^{7}$ Economic significance can be measured by multiplying the coefficient by one standard-deviation of the intensity variables. We see from the results that for a one standard-deviation increase in $I N T^{1}$ (i.e. 85.8 from Table 1), the quoted spread increases by roughly $0.1 \%$ compared with an average quoted spread of $0.75 \%$ before MAD and $0.47 \%$ after MAD (from Table 2). This is an economically significant effect. The magnitude of this effect is similar to what is found in Chung and Charoenwong (1998) for the US market. Our

\footnotetext{
6 Note that some companies in the dataset do not appear in both periods. Indeed, some stocks are traded only before MAD, while others appear only after its implementation. This means that the sample of companies is less than doubled using this methodology.

7 Due to the clustering of the residuals, the degrees of freedom is 83, and so the cut-off points of the $t$ statistics are $1.66,1.99$ and 2.64 for the 10,5 and $1 \%$ confidence levels, respectively.
} 
Table 3 Intensity of insider trading and stock liquidity

\begin{tabular}{|c|c|c|c|c|c|c|}
\hline & \multicolumn{2}{|l|}{ QS } & \multicolumn{2}{|l|}{ ES } & \multicolumn{2}{|l|}{ PI } \\
\hline & (1) & (2) & (1) & (2) & (1) & (2) \\
\hline Intercept & $\begin{array}{l}1.6680 \\
(2.48)\end{array}$ & $\begin{array}{l}1.7070 \\
(2.50)\end{array}$ & $\begin{array}{l}1.3599 \\
(2.07)\end{array}$ & $\begin{array}{l}1.3867 \\
(2.08)\end{array}$ & $\begin{array}{l}0.4090 \\
(3.92)\end{array}$ & $\begin{array}{l}0.4217 \\
(3.97)\end{array}$ \\
\hline $\log$ MCap & $\begin{array}{l}-0.0660 \\
(-1.43)\end{array}$ & $\begin{array}{l}-0.0671 \\
(-1.51)\end{array}$ & $\begin{array}{l}-0.0630 \\
(-1.37)\end{array}$ & $\begin{array}{l}-0.0650 \\
(-1.47)\end{array}$ & $\begin{array}{l}-0.0222 \\
(-1.90)\end{array}$ & $\begin{array}{l}-0.0238 \\
(-2.37)\end{array}$ \\
\hline InvPrice & $\begin{array}{l}1.0251 \\
(10.71)\end{array}$ & $\begin{array}{l}1.0354 \\
(10.48)\end{array}$ & $\begin{array}{l}1.0336 \\
(10.86)\end{array}$ & $\begin{array}{l}1.0429 \\
(10.74)\end{array}$ & $\begin{array}{l}0.0693 \\
(2.31)\end{array}$ & $\begin{array}{l}0.0694 \\
(2.50)\end{array}$ \\
\hline $\log V_{o l}$ & $\begin{array}{l}-0.0586 \\
(-1.02)\end{array}$ & $\begin{array}{l}-0.0625 \\
(-1.09)\end{array}$ & $\begin{array}{l}-0.0413 \\
(-0.73)\end{array}$ & $\begin{array}{l}-0.0439 \\
(-0.78)\end{array}$ & $\begin{array}{l}-0.0049 \\
(-0.42)\end{array}$ & $\begin{array}{l}-0.0045 \\
(-0.44)\end{array}$ \\
\hline Volty & $\begin{array}{l}0.6155 \\
(1.82)\end{array}$ & $\begin{array}{l}0.6128 \\
(1.82)\end{array}$ & $\begin{array}{l}0.5863 \\
(1.76)\end{array}$ & $\begin{array}{l}0.5847 \\
(1.77)\end{array}$ & $\begin{array}{l}0.0964 \\
(2.00)\end{array}$ & $\begin{array}{l}0.0963 \\
(2.00)\end{array}$ \\
\hline $\mathrm{INT}^{1}$ & $\begin{array}{l}0.0011 \\
(2.41)\end{array}$ & - & $\begin{array}{l}0.0011 \\
(2.40)\end{array}$ & - & $\begin{array}{l}0.0002 \\
(1.92)\end{array}$ & - \\
\hline $\mathrm{INT}^{2}$ & - & $\begin{array}{l}3.0576 \\
(1.53)\end{array}$ & - & $\begin{array}{l}3.5196 \\
(1.77)\end{array}$ & - & $\begin{array}{l}0.6417 \\
(0.86)\end{array}$ \\
\hline MAD & $\begin{array}{l}0.2093 \\
(1.29)\end{array}$ & $\begin{array}{l}0.2555 \\
(1.36)\end{array}$ & $\begin{array}{l}0.1952 \\
(1.22)\end{array}$ & $\begin{array}{l}0.2450 \\
(1.32)\end{array}$ & $\begin{array}{l}0.0323 \\
(1.33)\end{array}$ & $\begin{array}{l}0.0345 \\
(1.22)\end{array}$ \\
\hline $\mathrm{MAD} \times \mathrm{INT}^{1}$ & $\begin{array}{l}-0.0005 \\
(-0.89)\end{array}$ & - & $\begin{array}{l}-0.0005 \\
(-0.92)\end{array}$ & - & $\begin{array}{l}-0.0001 \\
(-0.88)\end{array}$ & - \\
\hline $\mathrm{MAD} \times \mathrm{INT}^{2}$ & - & $\begin{array}{l}-3.2653 \\
(-1.28)\end{array}$ & - & $\begin{array}{l}-3.4945 \\
(-1.40)\end{array}$ & - & $\begin{array}{l}-0.1771 \\
(-0.30)\end{array}$ \\
\hline$N$ & 135 & 135 & 135 & 135 & 135 & 135 \\
\hline Adj. $R^{2}$ & 0.7396 & 0.7385 & 0.7369 & 0.7364 & 0.6399 & 0.6394 \\
\hline
\end{tabular}

This table shows the effect of the intensity of insider trading on average stock liquidity, namely quoted spread and effective spread, and on permanent price impact. Two measures of intensity of insider trading are used. The first is the total number of shares traded by insiders for a given company, scaled by the number of shares outstanding. The second intensity measure is the proportion of trading days with insider trading. The explanatory variables are: $\log$ market capitalization (logMCap); the inverse of the average stock price (InvPrice); the log of the average daily volume (logVol); the daily volatility (Volty); insider trading intensity $\left(\mathrm{INT}^{1}\right.$ and $\mathrm{INT}^{2}$ ); a dummy variable that equals 1 after the Market Abuse Directive, and zero otherwise $(\mathrm{MAD})$; an interaction term between MAD and insider trading intensity $\left(\mathrm{MAD} \times \mathrm{INT}^{1}\right.$ and $\left.\mathrm{MAD} \times \mathrm{INT}^{2}\right)$. All variables are computed using all dates for which the companies are traded on Euronext Amsterdam, from July 2004 until end of December 2007. Robust $t$ statistics are shown in brackets

results for the effective spread are similar than for quoted spread. For the permanent price impact, the results are weaker: an increase of one standard deviation of INT ${ }^{1}$ increases PI by about $0.02 \%$. But this has to be compared with an average price impact of $0.15-0.16 \%$, which makes it still economically significant. Results for model (2) using $I N T^{2}$, the proportion of days with insider trading, are of similar magnitude, although the regression results show that the statistical significance is lower. Overall, the regression results clearly show that a larger amount of insider trading harms market liquidity and adverse selection. 
Care has to be taken in the interpretation of the coefficient for the Market Abuse Directive dummy. This coefficient might capture some differences between the two periods that are not due to the regulation per se. For example, it is well known that liquidity increases over time (this can be seen in the descriptive statistics in Table 2), thus a negative coefficient is to be expected even if the new regulation did not have any effect on liquidity. But what is observed is a positive coefficient, although not significant. This is surprising because the result of MAD is to increase the penalty to illegal insider trading as well as obliging companies to publish more information in the form of press releases. This should lower the information asymmetry between insiders and outside investors, and thus reduce the price impact. We do not observe this effect.

The interaction term between $M A D$ and $I N T^{k}$ aims at capturing whether the Market Abuse Directive helped to reduce the impact of insider trading on stock liquidity. All models have negative coefficients. These negative coefficients mean that the intensity of insider trading is affecting less stock liquidity after the implementation of the new regulation. However, the results are not statistically significant.

The results are similar to Frijns et al. (2008) but in their paper, only the price impact, or the information content of trades, seems to be reduced due to the new regulation. ${ }^{8}$

This section showed that the average liquidity of stocks is affected by the intensity of insider trading. The next section will investigate whether insiders have an effect on the stock liquidity on days of their trades.

\section{Stock Liquidity Around Dates of Legal Insider Trading}

In this section, we want to analyze whether insiders affect stock liquidity and price impact on the exact day when they trade. Before to start with the analysis of Abnormal Illiquidity, we show the price impact curve, similar to Fig. 2, but this time separating days when insiders trade (dashed lines) from days with no insider trading (solid line). The graph can be seen in Fig. 3. We see that the price impact is in average larger on days of insider trading. This is especially pronounced for small cap firms, where the average price impact on days without insider trading is about $0.36 \%$, while on insider trading days, the average price impact reaches $0.48 \%$.

Table 2 also shows how liquidity and adverse selection changes between days of insider trading and days without insider trading. We can see that quoted spreads (Panel A) and effective spreads (Panel B) are qualitatively larger on days of insider trading compared to days without insider trading. Surprisingly, this is the case only for small firms and large firms. It is not the case for medium firms. For the permanent price impact (Panel C), this adverse selection measure is larger on insider trading days compared to non-insider trading days for all firms sizes.

To give an example of how much this change in liquidity affects trading costs, assume an investor trades for $€ 10,000$ of a large stock, after the Market Abuse Direc-

\footnotetext{
8 The difference between our results and those of Frijns et al. (2008) may be due to methodology. They use model-based methodologies for decomposing the bid-ask spread into its components (Madhavan et al. 1997; Glosten and Harris 1988) while we use a model-free methodology which is feasible thanks to the richness of the data.
} 


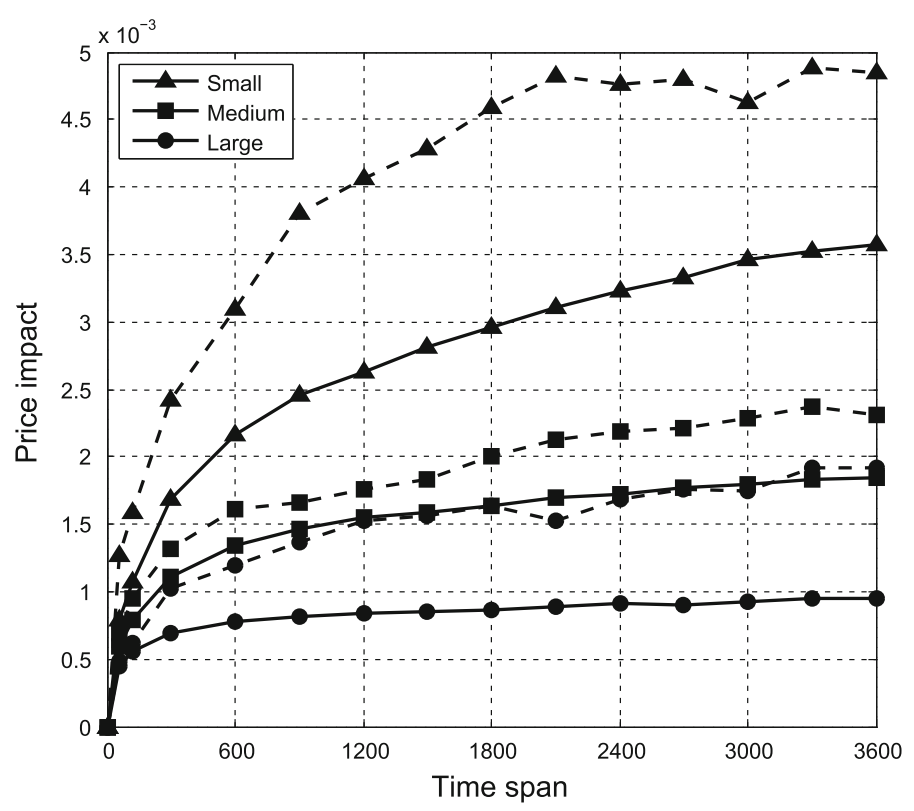

Fig. 3 Price impact with and without insider trading. This figure shows the mean price impact, broken down into size terciles, on dates with insider trading (dashed line) and dates without insider trading (solid lines). The price impact is scaled by the quote mid-point. Time is in seconds. Days without insider trading are 10 days preceding and 10 days following insider trading

tive has passed. The implicit trading cost, not accounting for commissions and fees, is best represented by the effective spread. In our case, it would be $0.118 \% / 2$ (the trader pays half the spread for a single trade), i.e. $€ 5.90$. On days of insider trading, this cost would jump to $€ 47.40 / 2=€ 23.70$. This cost could be further decomposed into information asymmetry costs and liquidity costs. The part due to information asymmetry is $0.062 \% / 2$, i.e. $€ 3.10$ on days without insider trading, and $€ 5.15$ on days of insider trading.

\subsection{Abnormal Illiquidity}

To analyze the change in liquidity and price impact due to insider trading, for each company-date pair, we use the Abnormal Illiquidity measure, defined in Sect. 2.1, above. Figure 4 shows the Abnormal Illiquidiy and Cumulative Abnormal Illiquidity for each liquidity measure (quoted spread, effective spread and price impact), and for each size category (small, medium, large).

We see from Fig. 4 that for small firms, all Abnormal Illiquidity measures are different from zero at day zero, i.e. on the insider trading day, but not afterwards. The Cumulative Abnormal Price Impact remains statistically different from zero on day 1 and on day 4. This means that insiders induce an increase in illiquidity on the date at which they trade. This increase is important as it is close to 5 basis points for the quoted spread and the effective spread, and close to 10 basis points for the price impact. 
These numbers can be compared with the average values for the liquidity measure in the sample provided in Table 2, where we see that the average effective spread is about $1.35 \%$ of the share price before MAD and $0.70 \%$ after MAD. So an abnormal effective spread on insider trading day of $0.05 \%$ is an economically non-negligible increase.

Medium firms show a different pattern than small firms on date of insider trading for the Abnormal Quoted Spread and the Abnormal Effective spread. The average Abnormal Illiquidity is negative for these measures, but not statistically different from zero. However, the Abnormal Price Impact is positive and significant: an increase of about 3 to 4 basis points (compared to an average before MAD of $0.19 \%$ and of $0.16 \%$ after MAD).

Figure 4 shows as well that large firms are not systematically affected in their liquidity on days of insider trading. The Abnormal Illiquidity is close to zero and non significant on day zero. However, there is a pattern of increasing Cumulative Abnormal Illiquidity for this size category. For the effective spread and the price impact, the $C A I$ reaches a significant 7 basis points on day 4 . There is a similar increase for the quoted spread, but it is not statistically significant. This means that for large firms, the liquidity measures react with a delay to insider trading. This pattern can be explained by the fact that there is a large number of trades during a day for this firm size, and thus the insiders can hide better their trades, so that it takes more time for liquidity providers to detect and react to the presence of insiders on the market. This result is similar to the findings in Gleason (2007) where the author observes that NASDAQ stocks with a larger number of dealers (i.e. larger stocks) are less affected by insider trading in terms
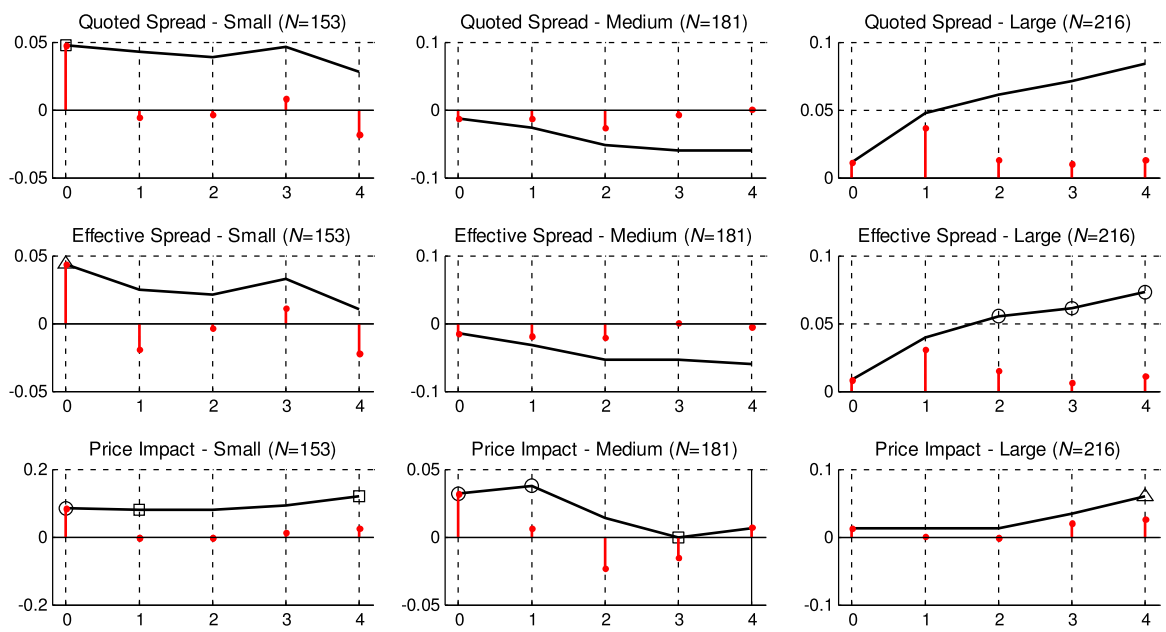

Fig. 4 Cumulative Abnormal Illiquidity for different market capitalization. These graphs show the Abnormal Illiquidity (vertical lines) and the Cumulative Abnormal Illiquidity (line plot) for the three spread measures (quoted spread, effective spread and price impact), and for the three size categories. In each graph, the $\mathrm{x}$ axis represents the day after insider trading date (day zero is the insider trading day itself), and the $y$ axis is the Abnormal Illiquidity, in percentage points. The marker represents the significance level. A triangle means significant at the $10 \%$ level; a square means significant at the $5 \%$ level; a circle means significant at the $1 \%$ level. See text for details about data and methodology 
of bid-ask spread. Also, Khan et al. (2005) finds that for the largest 100 NASDAQ stocks, the bid-ask spread widens with delay to insider sales, and the authors interpret this results as dealers trying to recover their loss over time after insider trading. A similar interpretation can be made for our results.

\subsection{Cross-Sectional Analysis of CAI}

To study more in details the determinants of Abnormal Illiquidity, we use a regression framework where the Cumulative Abnormal Illiquidity is regressed on explanatory variables. The following regression is performed:

$$
\begin{aligned}
& C A I_{i}=\beta_{0}+\beta_{1} B U Y_{i}+\beta_{2} \text { Ret }_{i}+\beta_{3} \text { Ret } \times B U Y_{i}+\beta_{4} \log \text { Holding }_{i} \\
& +\beta_{5} \log \operatorname{InsTrS} z_{i}+\beta_{6} \operatorname{Volty}_{3} m_{i}+\beta_{7} M A D_{i}+\varepsilon_{i},
\end{aligned}
$$

where $C A I_{i}$ is the Cumulative Abnormal Illiquidity (either for quoted spread, effective spread or price impact) over day 0 and $1^{9}$ for insider trading event $i ; B U Y_{i}$ is a dummy variable indicating insider purchases, Ret $_{i}$ is the average return of the stock during 10 days prior to (but not including) the insider trading day; Ret $\times B U Y_{i}$ is an interaction term to analyze the effect of stock return when there is an insider purchase. $\log$ Holding $_{i}$ and $\log \operatorname{Ins} \operatorname{Tr} S z_{i}$ are the holding of the insider and the size of the trade, respectively. Volty $3 m_{i}$ is the volatility of the stock computed during the three months prior to the event, and finally, $M A D_{i}$ is a dummy that equals 1 after the implementation of the Market Abuse Directive (October 2005). In this regression, we use stock fixedeffects, so the coefficients estimated are to be interpreted as within firm effects. ${ }^{10}$ Results are shown in Table 4.

The coefficients of the purchase dummies are small, but for the price impact equation, the dummy is significant at the $5 \%$ level. This result shows that when insiders buy shares, they affect price impact to a lesser extent than when they sell. This is surprising given that insider purchases are known to have higher information content (in the sense that insider purchases can predict future stock returns, as shown in the literature). But here, results show that market participants, on the short run, react stronger when insiders sell shares than when they buy.

Looking at the coefficient of Ret, we see that it is negative, large and significant for quoted spread and effective spread. Since the coefficients of $\operatorname{Reg} \times B U Y$ are insignificant, it means that an insider trade following an increase in stock price affects negatively the Cumulative Abnormal Illiquidity. In other terms, an insider trade after a run-up in price does not affect liquidity of the stock. But on the contrary, an insider trade following a decrease in stock price strongly affects liquidity. It might be that market participants are more nervous and are prone to withdraw liquidity after a decline in prices.

\footnotetext{
${ }^{9}$ CAI over day 0 and 1 is used as the dependent variable instead of simply the abnormal illiquidity on day zero because if the trade by the insider occurs close to the closing time, or after the closing time, other market participants might react to it the next trading day.

10 Note that with this specification, the cross-sectional determinants of the liquidity measures, like firm size or trading volume, are captured by the unobserved effects.
} 
Table 4 Regression of cumulative abnormal illiquidity on explanatory variables

\begin{tabular}{llll}
\hline & CAI-QS & CAI-ES & CAI-PI \\
\hline BUY & -0.0811 & -0.0952 & -0.0667 \\
& $(-0.99)$ & $(-1.00)$ & $(-1.99)$ \\
Ret & -3.0327 & -2.3642 & 2.7150 \\
& $(-1.90)$ & $(-2.39)$ & $(0.71)$ \\
Ret $\times$ BUY & 1.0765 & 0.5080 & -3.1341 \\
& $(0.52)$ & $(0.35)$ & $(-0.73)$ \\
$\operatorname{logHolding}$ & 0.0449 & 0.0362 & -0.0178 \\
& $(0.90)$ & $(0.78)$ & $(-0.37)$ \\
$\log I n s T r S z$ & -0.0273 & -0.0245 & -0.0118 \\
& $(-1.57)$ & $(-1.56)$ & $(-0.89)$ \\
Volty3m & -0.0020 & 0.1827 & -1.0757 \\
& $(-0.01)$ & $(0.91)$ & $(-2.08)$ \\
MAD & -0.0519 & 0.0041 & -0.0565 \\
& $(-1.14)$ & $(0.18)$ & $(-1.10)$ \\
$N$ & 597 & 597 & 597 \\
Adj. $R^{2}$ & 0.0138 & 0.0085 & 0.0453 \\
\hline
\end{tabular}

This table shows the regression results of Cumulative Abnormal Illiquidity (CAI) on explanatory variables. BUY is a dummy variable indicating a purchase by insider. Ret is the return of the stock 10 days prior to the insider trading event. Ret $\times$ BUY is an interaction variable between Ret and BUY. logHolding is the log of the prior holding of the insider in shares scaled by the number of shares outstanding. $\log I n s T r S z$ is the $\log$ of the size of the trade in shares scaled by the number of shares outstanding. Volty $3 \mathrm{~m}$ is the stock's daily volatility computed three months prior to the insider trade. MAD is a dummy that equals one after the implementation of the Market Abuse Directive. Stock fixed-effects are used (not shown). Robust $t$ statistics are shown in brackets

The coefficients on $\log H$ olding and on $\log \operatorname{Ins} \operatorname{Tr} \mathrm{Sz}$ are not significant: the size of the trade and the prior holding of the insider are not important to explain the liquidity effects of their trades. Volty $3 m$ is important only for abnormal price impact, with a negative coefficient. This means that when insiders trade in periods of large volatility, they affect less the price impact compared to periods of low volatility. This can be understood as large volatilities can help the insider to hide better his trades to other market participants. Or alternatively, when volatility is high, the price impact is already higher than usual, as can be seen in Table 2, above.

The regression results show also that once we control for the relevant explanatory factors, the effect of the Market Abuse Directive on the Abnormal Illiquidity is not significant. The new regulation does not help to reduce the impact of insider trading on liquidity and price impact.

The results in this section can be summarized as follows. In a univariate analysis, we find that small firms are the ones for which liquidity reacts the most to legal insider trading: 5 basis points for the quoted and effective spread, and 10 basis points for the price impact. For medium-sized firms, only the price impact increases. For large firms, Fig. 4 suggests that the $C A I$ increase with a delay of a couple of days after insider trading. This shows that in average, trades by insiders affect the liquidity of their 
stocks and the permanent price impact around the dates at which they trade. Next, we investigated what could be the determinants of this short-term change in liquidity and price impact. A regression analysis with stock fixed-effects shows that the size of the insider trade and the insider's prior holding do not affect abnormal liquidity. The most important determinants of Abnormal Illiquidity is the return of the stock prior to the trade by an insider: when the stock has negative returns prior to the trade, the insider induces a larger effect on the quoted spread and effective spread. And vice versa: when the stock increases before the trade, the effect of insider trading on liquidity is reduced. The determinants of the abnormal price impact are different: sales by insiders have a larger effect on price impact than purchases. Also, stock volatility negatively explains abnormal price impact.

\section{Conclusion}

Insider trading is a regulated activity in most of the countries around the world. Even if insiders are prohibited by law to trade upon private and price-sensitive information, their trades are in average more information driven than those of outside investors. In this paper, we use legal trades by corporate insiders to analyze whether the presence of insiders on the market affects liquidity measures on the stock market as well as adverse selection. This study is done in the context of the implementation of a European-wide regulation, the Market Abuse Directive, that enhanced market surveillance and insider trading regulations. In order to do so, we use legal insider trading data from the Netherlands on Dutch listed companies.

Using a first approach, we perform a cross-sectional regression of the average liquidity and price impact of each stock on their determinants and on a proxy for the intensity, or prevalence, of insider trading. This allows us to estimate whether the average liquidity and price impact are larger when insider trading is high, compared to stocks where insider trading is low. We find that intensity of insider trading is an important determinant of stock market liquidity and adverse selection. Also, we find some evidence that the new regulation helps to reduce the effect of insider trading on liquidity: after the implementation of the regulation, the variable intensity is a less important factor explaining liquidity and price impact.

In a second approach, we focus on the short term, and we measure whether insider trading affects liquidity and price impact on the days around their trades, compared to a normal liquidity and price impact level. We find that for small stocks, quoted spread, effective spread and price impact are all affected immediately on the day of insider trading. For medium firms, only the price impact changes on insider trading dates, not the other liquidity measures. For large firms, we find an impact but with a delay of two to four days after the date of transaction, as if market participants react late to the presence of a potentially informed trader. Finally, we test what could be the determinants of the effect insiders have on liquidity and price impact when they trade. For the quoted and effective spread, we find that it is mostly the return of the stock prior to the insider trading event that counts. For the price impact, we find that the effect induced by insiders depends on whether the trade is a purchase or a sale, and also on the volatility of the stock prior to the trade. 
An important contribution of this paper is to test the ability of the European Union directive, implemented in the Netherlands as the Market Abuse Decree, to improve liquidity and reduce adverse selection. We find that stock average liquidity and price impact are less affected by the intensity of insider trading after the implementation of the regulation. This means that even if legal insider trading remains prevalent after the regulation, outside traders do not find it a threat and so liquidity and price impact are less affected by it. This is true in average. Our second approach, looking specifically on dates of insider trading, did not find that liquidity and price impact are less affected by insider trading after the regulation was passed.

Further analyses have to be done on this topic to understand the link between insider trading and stock liquidity. First and foremost, a better understanding of the dynamics of liquidity is called for, from which the specific impact of insider trading could be better identified.

Open Access This article is distributed under the terms of the Creative Commons Attribution 4.0 International License (http://creativecommons.org/licenses/by/4.0/), which permits unrestricted use, distribution, and reproduction in any medium, provided you give appropriate credit to the original author(s) and the source, provide a link to the Creative Commons license, and indicate if changes were made.

\section{References}

AFM (2007). The effects of a change in market abuse regulation on stock prices and volumes: Evidence from the Amsterdam stock market, The Netherlands Authority for the Financial Markets report (2007)

Aktas, N., de Bodt, E., Declerck, F., \& Van Oppens, H. (2007). The PIN anomaly around M\&A announcements. Journal of Financial Markets, 10, 169-191.

Aktas, N., de Bodt, E., \& Van Oppens, H. (2008). Legal insider trading and market efficiency. Journal of Business Finance and Accounting, 32, 1379-1392.

Amihud, Y., \& Mendelson, H. (2008). Liquidity, the value of the firm, and corporate finance. Journal of Applied Corporate Finance, 20, 32-45.

Bainbridge, S. (2000). Insider trading. In Encyclopedia of law and e conomics III. Cheltenham, U.K.: Edward Elgar Publishing.

Bessembinder, H., \& Kaufman, H. M. (1997). A comparison of trade execution costs for NYSE and NASDAQ-listed stocks. The Journal of Financial and Quantitative Analysis, 32, 287-310.

Bhattacharya, U., \& Daouk, H. (2002). The world price of insider trading. The Journal of Finance, 57, 75-108.

Campbell, J. Y., Lo, A. W., \& MacKinlay, A. C. (1997). The econometrics of financial markets. Princeton, NJ: Princeton University Press.

Cheng, L., Firth, M., Leung, T. Y., \& Rui, O. (2006). The effects of insider trading on liquidity. Pacific-Basin Finance Journal, 14, 467-483.

Chung, K. H., \& Charoenwong, C. (1998). Insider trading and the bid-ask spread. The Financial Review, $33,1-20$.

Cziraki, P., de Goeij, P., \& Renneboog, L. (2013). Corporate governance rules and insider trading profits. Review of Finance, 18, 67-108.

de Jong, F., \& Rindi, B. (2009). The microstructure of financial markets. Cambridge, UK: Cambridge University Press.

Degryse, H., de Jong, F., \& Lefebvre, J. (2014). An empirical analysis of insider trading in the Netherlands. De Economist, 162, 71-103.

Demsetz, H. (1968). The cost of transacting. Quarterly Journal of Economics, 82, 33-53.

Fidrmuc, J., Goergen, M., \& Renneboog, L. (2006). Insider trading, news releases and ownership concentration. The Journal of Finance, 61, 2931-2974.

Frijns, B., Gilbert, A., \& Tourani-Rad, A. (2008). Insider trading, regulation and the components of the bid-ask spread. Journal of Financial Research, 31, 225-246. 
Garfinkel, J. A., \& Nimalendran, M. (2003). Market structure and trader anonymity: An analysis of insider trading. Journal of Financial and Quantitative Analysis, 38, 591-610.

Gleason, K. I. (2007). Does market maker competition affect the response to insider trading? Applied Financial Economics, 17, 691-700.

Glosten, L., \& Milgrom, P. (1985). Bid, ask and transaction prices in a specialist model with heterogeneously informed traders. Journal of Financial Economics, 14, 71-100.

Glosten, L. R., \& Harris, L. E. (1988). Estimating the components of the bid/ask spread. Journal of Financial Economics, 21, 123-142.

Huang, R. D., \& Stoll, H. R. (1996). Dealer versus auction markets: A paired comparison of execution costs on NASDAQ and the NYSE. Journal of Financial Economics, 41, 313-357.

Jeng, L. A., Metrick, A., \& Zeckhauser, R. (2003). Estimating the returns to insider trading: A performanceevaluation perspective. Review of Economics and Statistics, 85, 453-471.

Kavajecz, K. A. (1999). A specialist's quoted depth and the limit order book. The Journal of Finance, 54, 747-771.

Khan, W. A., Baker, H. K., Chaudhry, M., \& Maheshwari, S. K. (2005). The impact of insider trading on market liquidity in the NASDAQ market. Journal of Applied Business Research, 21, 11-22.

Krinsky, I., \& Lee, J. (1996). Earnings announcements and the components of the bid-ask spread. The Journal of Finance, 51, 1523-1535.

Kyle, A. (1985). Continuous auctions and insider trading. Econometrica, 53, 1315-1335.

Lakonishok, J., \& Lee, I. (2001). Are insiders' trades informative? Review of Financial Studies, 14, 79-112.

Lee, C. M. C., Mucklow, B., \& Ready, M. J. (1993). Spreads, depths, and the impact of earnings information: An intraday analysis. Review of Financial Studies, 6, 345-374.

Madhavan, A., Richardson, M., \& Roomans, M. (1997). Why do security prices change? A transaction-level analysis of NYSE stocks. Review of Financial Studies, 10, 1035-1064.

O’Hara, M. (1995). Market microstructure theory. Cambridge, MA: Blackwell Publishers.

Seyhun, H. N. (1998). Investment intelligence from insider trading. Cambridge, MA: The MIT Press.

Stoll, H. R. (2000). Friction. The Journal of Finance, 55, 1479-1514. 